\title{
REESCRITAS DE PEÇAS DE SHAKESPEARE PARA O PÚBLICO JOVEM: A SÉRIE MANGÁ SHAKESPEARE
}

\author{
Marcia do Amaral Peixoto Martins* \\ Pontifícia Universidade Católica do Rio de Janeiro
}

\begin{abstract}
Resumo: Este artigo enfoca reescritas de peças de Shakespeare voltadas para o público jovem e publicadas sob forma de quadrinhos japoneses na série Manga Shakespeare, publicada pela editora inglesa SelfMadeHero, e disponíveis em português do Brasil pela Galera Record, com destaque para a adaptação de Hamlet. Após uma apresentação geral da proposta da série inglesa e dos títulos já publicados, pelo menos dois níveis de reescrita de Hamlet serão examinados: inicialmente, a adaptação da peça para mangá, um processo que não só agrega multimodalidade ao produto final mas que também pode implicar mudanças concernentes a tempo e espaço, entre outras. Mais adiante, a ênfase recairá sobre a tradução interlingual do texto adaptado e dos paratextos, que resultaram na edição brasileira que integra a série intitulada Mangá Shakespeare. Para ambos os níveis de reescrita serão verificados: (i) aspectos gerais das transposições; (ii) o grau de manutenção das principais características da obra com respeito a tema, trama, desenho dos personagens e linguagem; e (iii) a imagem do autor e da obra que resulta do trabalho de reescrita.
\end{abstract}

Palavras-chave: Shakespeare. Adaptação. Mangás.

\footnotetext{
* Marcia A. P. Martins tem formação em Letras (habilitação Tradutor-Intérprete) pela PUC-Rio, Mestrado em Linguística pela mesma universidade e Doutorado em Comunicação e Semiótica pela PUCSP. Em 2012 realizou estágio pós-doutoral na Queen Mary University of London. É membro do corpo docente do Bacharelado em Letras-Tradução (inglês-português) e do Programa de Pós-Graduação em Estudos da Linguagem do Departamento de Letras da PUC-Rio, Rio de Janeiro, RJ, Brasil. Email: mmartins@puc-rio.br
} 


\title{
REWRITINGS OF SHAKESPEARE'S PLAYS FOR YOUNG READERS: THE MANGA SHAKESPEARE SERIES
}

\begin{abstract}
This paper discusses rewritings of Shakespeare's plays aimed at young readers and published as comics in the series Manga Shakespeare featured by the British publishing house SelfMadeHero and available in Brazilian Portuguese under the Galera Record label, with special focus on the adaptation of Hamlet. Following a presentation of the aims of the English manga series and of the plays already published, at least two levels of Hamlet's rewriting will be examined: firstly, its adaptation into manga, a process which not only adds multimodality to the final product but also entails changes concerning time and place. Secondly, the interlingual translation of the adapted text and of the paratexts, which resulted in the Brazilian edition that belongs to the series Mangá Shakespeare. For both levels of rewriting we will try to determine: (i) overall features of the transpositions; (ii) to what extent the main characteristics of the works regarding theme, plot, character design, and language are maintained; and (iii) which image of the writer and of the work is created by the rewriters.
\end{abstract} Keywords: Shakespeare. Adaptation. Mangas.

O legado de Shakespeare está cada vez mais vivo, graças à constante encenação das peças, às inúmeras (re)edições de suas obras no original e em traduções, inclusive incorporando novos títulos, e às inovadoras e criativas adaptações para outros meios, desde os mais tradicionais, como cinema, ópera e balé, até os quadrinhos e videogames, que agradam aos jovens e atraem mais aficionados.

Dessas novas reescritas, destacam-se pela quantidade e, muitas vezes, pela qualidade as adaptações para quadrinhos, voltadas a princípio para o público jovem mas que também podem interessar a leitores de outras faixas etárias. A série inglesa Manga Shakespeare, com alguns títulos já traduzidos para o português, é uma boa ilustração dessa tendência recente, ao adaptar as peças para esse formato de HQ no estilo japonês. Diante da originalidade do projeto e do seu potencial para disseminar as criações shakespearianas, decidi examinar o material disponível a fim de verificar como essas reescritas são feitas, em que medida são preservadas as principais 
características das peças e qual imagem do autor e das obras é transmitida para o público alvo.

No entanto, antes de prosseguir, creio que cabe definir o que denomino "reescrita". Não se trata simplesmente de um outro significante para designar "tradução", tendo com esse termo uma relação de sinonímia, mas sim de um novo conceito de tradução que, na verdade, implica uma relação de hiponímia entre tradução e reescrita, como será visto mais adiante. Em minha concepção, reescrita pressupõe um entendimento de tradução como transformação, realizada num movimento de articulação do texto e do sistema que o produziu com outras práticas institucionalizadas. A reescrita, tal como a entende André Lefevere, é o resultado de um processo tradutório que está necessariamente sujeito a coerções que dizem respeito à poética e à ideologia vigentes à época no sistema cultural de recepção. $\mathrm{O}$ conceito em questão não se refere apenas à tradução - que para o mesmo Lefevere é a modalidade mais importante de reescrita - mas também à crítica, organização de antologias, historiografia, edições condensadas, adaptações etc. No caso da literatura, as reescritas constroem "imagens" de obras e autores em outra cultura, ou mesmo de períodos, gêneros ou sistemas literários como um todo (Lefevere, 2007, p. 18 et seq.).

Voltando então às adaptações de Shakespeare para quadrinhos, mais especificamente para mangás, estas são direcionadas ao público jovem, o que remete à definição desse segmento de leitores e das categorias tradicionais de literatura "infantil" e "juvenil" e sua fusão, a literatura "infantojuvenil”. Uma distinção tradicional entre a literatura infantil e a juvenil, difundida inclusive em fontes de consulta populares como a Wikipedia ${ }^{1}$, estipula que a primeira destina-se a crianças entre dois a 10 anos de idade, caracteriza-se pela ausência de temas não apropriados para essa faixa etária - como guerras e crimes hediondos, por exemplo - e apresenta crianças como os principais personagens das histórias, cuja extensão média varia de 80 a 100 páginas. Já a literatura juvenil seria voltada para leitores entre 10 a 15 anos de idade, com temática mais complexa, personagens igualmente adolescentes e histórias 
variando de 200 a 300 páginas. No entanto, não é bem isso que se observa atualmente. "Literatura juvenil" é, aparentemente, um conceito mercadológico, que varia de editora para editora, de série para série. Pode abarcar desde adolescentes apenas, até esse segmento mais o de jovens adultos, indo dos 10 ou 12 até os 20 e poucos anos. Inclusive o termo "literatura jovem" está sendo mais usado do que "literatura juvenil"; embora pareçam sinônimos, aparentemente o adjetivo "juvenil" é mais restrito, pois deixa de fora o público categorizado como "jovem adulto".

A partir de contato com algumas editoras no Brasil que publicam adaptações voltadas para leitores jovens, ${ }^{2}$ foi possível perceber que o critério utilizado por elas difere da forma como os estudiosos da literatura infantil e juvenil dividem esses dois campos; isso se dá, naturalmente, devido à diferença de objetivos. Enquanto os estudiosos buscam analisar esses fenômenos a partir de sua história, que é recente no Brasil, as editoras precisam dividir seus autores e narrativas em grupos, para que cada criança ou jovem leia um livro que possa entender e com o qual possa se identificar.

Vejamos aqui como são feitas essas categorizações por dois grupos editoriais que trabalham com adaptações de peças de Shakespeare para a linguagem dos quadrinhos, a saber, Record e Autêntica. O Grupo Editorial Record tem dois selos, Galerinha e Galera, voltados para os públicos infantil (o primeiro) e juvenil e jovem adulto (o segundo). Desse modo, propõe um sistema de divisão exclusivo por faixa etária, no qual os leitores são divididos em três grupos:

público infantil: leitores até 9 anos;

público juvenil: leitores entre 10 e 14 anos;

público jovem adulto: leitores com mais de 14 anos.

Segundo esclarecimento da própria editora, o público leitor das adaptações de Shakespeare seria o público jovem adulto, que já se encontra no final do ensino fundamental ou no ensino médio.

A editora Autêntica, por sua vez, disponibiliza um extenso catálogo com títulos voltados para o público infantil e juvenil (http://gru- 
poautentica.com.br/download/catalogo-infantil-por.pdf). A divisão que faz dentro desses dois campos é bastante detalhada, com ênfase em temas que podem ser abordados em sala de aula pelos professores e narrativas com as quais as crianças e os adolescentes podem se relacionar. De forma resumida, a categorização é a seguinte:

i. pré-leitor: primeira infância (de 15 meses a 3 anos) e segunda infância (2 e 3 anos em diante);

ii. leitor iniciante: 6 e 7 anos em diante;

iii. leitor em processo: 8 e 9 anos em diante. Aqui começam a surgir as adaptações, como de Alice através do espelho, de Lewis Carroll;

iv. leitor fluente: 10 e 11 anos em diante;

v. leitor crítico: 12 e 13 anos em diante. Para esse leitor há inclusive títulos de poesia e filosofia.

Independentemente de como se organizam as faixas etárias, o fato é que o público de jovens leitores está em plena expansão, o que contradiz a impressão corrente de que a juventude de hoje é pouco afeita aos livros. Segundo a matéria intitulada "O papel dos games”, publicada na VejaRio de 28 de agosto de 2013,

[o] mercado literário brasileiro exibe um grande vigor. Nunca se vendeu tanto livro no país, num impulso que vem da emergente classe $\mathrm{C}$ e, principalmente, dos jovens em geral. No ano passado, pela primeira vez a venda de títulos destinados a esse segmento ultrapassou o volume daqueles voltados para os adultos: 47 milhões vs. 38 milhões de exemplares. Atentas ao filão, grandes editoras, como a Record, Cia. das Letras, Leya, Rocco e Objetiva investem pesado em selos específicos para esta camada da população. (Briso, 2013, p. 32)

Confirmando a tendência, a $16^{\mathrm{a}}$. Bienal dos Livros, realizada em 2013, registrou o maior público jovem de sua história. A porcenta- 
gem de visitantes entre 14 e 29 anos subiu de $44 \%$, em 2011, para $51 \%$. Foi introduzido um espaço dedicado aos jovens, denominado \#acampamento, cujo curador, João Alegria, revela ter-se surpreendido ao ver um público jovem com experiência de leitura e muito interesse pelos livros, que já chegava com listas de títulos para comprar e participava dos debates (Freitas, 2013, p. 16). A julgar pelos catálogos das editoras estrangeiras, esse fenômeno é internacional.

Diante, portanto, desse público crescente, ávido por consumir literatura em suas várias formas, os selos e séries não param de fazer lançamentos voltados para o público jovem, contemplando tanto textos originais como traduções e adaptações, dentre as quais se destacam as transposições de clássicos para quadrinhos. Observa Ricardo Rodrigues, um dos sócios da Comix, livraria paulista especializada na venda de quadrinhos: "Quando fundamos a Comix [há 27 anos], havia uns 25 títulos em quadrinhos mensais, como revistas da Disney e da Turma da Mônica. Hoje já são 125 por mês. Antes era coisa de nerd, mas agora parece que ser nerd ficou na moda" (Meireles, 2013, p. 13).

O sucesso dos quadrinhos entre os jovens valoriza o gênero como modalidade de adaptações de clássicos, antes restritas basicamente a versões condensadas ou romances em prosa. Mais uma vez, no entanto, cabe fazer um esclarecimento conceitual, agora com referência ao termo "adaptação". Em relação ao termo, é fato que existe uma pletora de conceitos muito próximos, que muitas vezes se sobrepõem e são difíceis de definir. Podemos falar, por exemplo, de apropriação, de releitura, de paródia, ou mesmo de adaptação no sentido dos ajustes necessários para a transposição de um texto de uma língua/cultura para outra - isto é, tradução stricto sensu. No entanto, entendo adaptação no sentido jakobsoniano de tradução intersemiótica, ou então de uma reescrita voltada para outro tipo de público que não o visado originalmente: por exemplo, um público inserido em outra cultura, como acontece com peças de teatro, ou um público de outra faixa etária, com outro nível de instrução; ou ainda de uma reescrita que promova mudanças como de cenário ou de época. 
Buscando examinar e aprofundar as inúmeras definições e práticas que se encaixam nos rótulos de "adaptação" e "apropriação", Julie Sanders (2006, p. 18-19) apresenta algumas possibilidades de prática da primeira, que podem ser assim resumidas: a) a transposição de um gênero para outro (por exemplo, da literatura para o cinema, do teatro dramático para o musical, do drama para a ficção em prosa); b) a intervenção nos textos por meio seja de cortes e omissões (similar à editoração), seja de acréscimos, expansões e interpolações (que podem, inclusive, ser sob forma de comentário, dando voz aos silenciados no texto de origem ou explicitando razões hipotéticas para as ações dos personagens); c) a tentativa de tornar os textos "relevantes" ou facilmente compreensíveis para novos leitores e espectadores por meio de aproximações e atualizações (motivação de inúmeras adaptações dos chamados "clássicos" para a televisão e o cinema). Nesse caso, o novo ambiente cultural e/ou época e/ou cenário geográfico não precisa $(\mathrm{m})$ envolver necessariamente uma mudança de gênero. É, portanto, esse território de limites relativamente definidos que circunscreve o conceito de adaptação com o qual trabalho. Proponho que outras modalidades de reescrita com maior latitude ou grau de intervenção recebam definições e denominações específicas, mesmo sabendo que estas são meras construções discursivas. Minha preocupação é não esgarçar demais as fronteiras conceituais, a ponto de não se conseguir mais distingui-las.

A adaptação dos clássicos para o formato de quadrinhos, inclusive os japoneses (mangás), é uma estratégia que vem sendo muito usada contemporaneamente, e já tem sido objeto de alguns estudos no campo disciplinar da tradução, como os produzidos por Alvaro Hattnher $^{3}$, da UNESP de São José do Rio Preto, e Nilce Pereira ${ }^{4}$, da mesma instituição.

\section{Um pouco sobre mangás}

A palavra "mangá" - resultado da transliteração de um termo em japonês que significa "história em quadrinhos" - é usada para 
designar quadrinhos no estilo japonês. Sua gênese está no Teatro das Sombras, manifestação artística de origem chinesa que na época feudal percorria diversos vilarejos contando lendas por meio de fantoches. Foi com a Restauração Meiji, em 1868, que surgiu a semente para a criação e popularização do mangá. A Restauração reabriu os portos japoneses para comerciantes ocidentais depois de mais de 200 anos de isolamento - e, com os comerciantes, também chegaram muitos jornalistas europeus que, além de escreverem para os jornais, desenhavam as charges políticas dos periódicos da época. Foram essas charges que inspiraram os ilustradores japoneses de mangá. Os mangás do século XIX, contudo, eram quase que exclusivamente voltados para o público adulto, devido à sua forte crítica política. Foi somente no início do século XX que os primeiros mangás infantis começaram a ser publicados (Vasconcellos, 2006). No Japão, os mangás ainda preservam sua incrível força e popularidade, sendo consumidos por japoneses de todas as faixas etárias e de todas as classes sociais. Além da origem distinta, os mangás japoneses diferem dos quadrinhos ocidentais em relação ao tamanho (um volume pode ter cerca de 200 páginas) e ao modo de representação gráfica utilizada. A leitura do mangá é oposta ao modelo ocidental de leitura: o livro começa daquilo que nós consideramos como o fim, e o texto é impresso da direta para a esquerda. Acrescente-se a esses aspectos o traço do desenho, que também é peculiar; os olhos, por exemplo, costumam ser bem grandes, o que acentua a expressividade dos personagens. $\mathrm{O}$ formato alcançou grande popularidade no Ocidente e circula não apenas em traduções mas também em edições originais, como as da série Manga Shakespeare, onde, no entanto, há uma ruptura da tradição japonesa de leitura, adotando-se a direção ocidental, da esquerda para a direita.

\section{A série Manga Shakespeare}

A série inglesa Manga Shakespeare da SelfMadeHero, uma editora independente que atua no segmento das novelas gráficas, 
inclusive em tradução, oferece edições muito bem acabadas, com ilustrações basicamente em preto e branco, e 14 títulos publicados até o momento (dos quais cinco já foram traduzidos para o português ${ }^{5}$ ): Romeo and Juliet, A Midsummer Night's Dream, Hamlet, Much Ado About Nothing, Macbeth, King Lear, Twelfth Night, Richard III, The Merchant of Venice, Othello, Henry VIII, The Tempest, As You Like It e Julius Caesar. A proposta da série é apresentada no seu próprio site (www.mangashakespeare.com) e na quarta capa das edições: "Manga Shakespeare is a series of graphic novel adaptations of William Shakespeare's plays. A fusion of classic Shakespeare with manga visuals, these are cutting-edge adaptations that will intrigue and grip readers." As linhas gerais das tramas e a linguagem shakespeariana original são preservadas, mas o texto é bem resumido e a ambientação das histórias pode mudar, o que resulta em dois ou mais níveis de adaptação: a) a transposição do gênero dramático para a linguagem dos quadrinhos; e b) a transposição para uma outra época, cultura e lugar geográfico (sendo que esse segundo item não precisa, necessariamente, ser visto como um só; podemos entendê-lo como constituindo diferentes instâncias de adaptação). As quatro grandes tragédias shakespearianas, por exemplo, são assim reescritas:

- a trama de Hamlet se passa no ano de 2107, depois que uma mudança global do clima deixou a Terra devastada. O planeta é um mundo cibernético em permanente expectativa de guerra;

- a Veneza de Othello é habitada por seres alados, sem distinção precisa entre homens e animais;

- a ação de King Lear é transposta para 1759, no auge das lutas entre nativos e invasores no território hoje conhecido como os Estados Unidos da América. O personagem-título é um venerado chefe moicano (Iroquois) cujas filhas Regan e Goneril têm um aspecto ocidentalizado, enquanto a terceira, Cordelia, tradicionalista que se apega aos costumes nativos, apresenta traços étnicos similares aos do pai; e 
- em um Macbeth futurista, guerreiros samurais buscam recuperar um mundo pós-nuclear habitado por mutantes.

Outra grande favorita, a tragédia lírica de Romeu e Julieta, é ambientada em um Japão contemporâneo, onde os dois jovens enamorados são envolvidos em uma vendetta entre famílias rivais da Yakuza, a máfia japonesa.

No site www.mangashakespeare.com são valorizadas a qualificação da equipe editorial e também o potencial educativo da série para ensino de literatura e de inglês como segunda língua, com ênfase na sua preocupação em condensar as peças de modo a destacar as cenas centrais. ${ }^{6}$ Ainda no site da série há vários comentários valorizando a linguagem dos mangás, ressaltando-se aspectos como a sua utilização como meio de instrução no Japão, a sua popularidade junto a jovens de ambos os sexos e a ampla gama de aplicações pedagógicas que oferece, inclusive aprovadas por uma série de órgãos governamentais britânicos ligados à educação.

O autor dos mangás ingleses, apresentado como adaptador, é Richard Appignanesi, que acumula a função de editor da série e tem um currículo respeitável, onde se destacam atividades editoriais e produção de obras de ficção e não ficção, além de um doutorado em história da arte clássica.

Na série Manga Shakespeare todas as peças têm o mesmo adaptador, embora os ilustradores sejam diferentes para cada uma; o nome do ilustrador tem mais destaque do que o do adaptador, constando na capa e na lombada do volume.

$\mathrm{Na}$ impossibilidade de analisar, no âmbito deste artigo, as 14 peças publicadas na série, mesmo que muito superficialmente, vou me concentrar aqui em apenas uma, que é Hamlet, não só por seu protagonismo no cânone shakespeariano mas também pelo fato de ser um dos cinco títulos já publicados em tradução na série Mangá Shakespeare ${ }^{7}$, da Galera Record, em tradução de Alexei Bueno, o que possibilita o estudo desse outro nível de reescrita, a tradução para o português. 


\section{O Hamlet do Manga Shakespeare}

Como já foi dito acima, o Hamlet em mangá se passa no século XXII, gerando dois níveis de adaptação: a que transformou a peça em história em quadrinhos e a que trouxe a ação para o século seguinte ao nosso, num mundo cibernético, de ficção científica. Em termos de apresentação, o exemplar, como os demais da série, tem formato de livro, com o personagem Hamlet na capa e o nome da ilustradora, que também aparece na lombada. O nome do adaptador aparece na folha de rosto e no expediente.

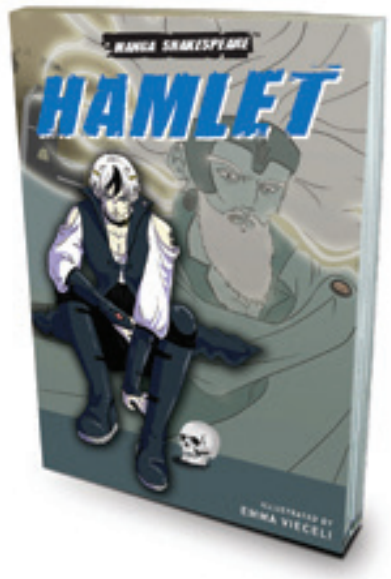

Figura 1: capa da edição da SelfMadeHero

A proposta da série como um todo e dessa peça em particular vem apresentada resumidamente em dois parágrafos na quarta capa, que ainda traz três painéis com cenas/falas emblemáticas, o endosso do Shakespeare's Globe e, como de praxe, um fragmento de resenha de um veículo prestigiado.

Os elementos paratextuais que pertencem ao interior do exemplar começam pela primeira página, com uma ilustração do personagem-título acompanhada de uma legenda explicativa sobre a 
ambientação futurista da trama, pós-catástrofe climática. As páginas seguintes apresentam os principais personagens com a respectiva ilustração e uma fala curta igualmente conhecida. A Polônio, por exemplo, apresentado como "Chamberlain of the Danish Court", é associada a frase "To thine own self be true", que é parte dos conselhos que dá a seu filho Laertes quando este vai para a França (Ato I, cena 3), enquanto que Ofélia é identificada por um pequeno fragmento da sua cena com a rainha Gertrudes, onde ela dá claros indícios de que está fora de seu juízo: “There's rosemary - that's for remembrance. And there is pansies - that's for thoughts" (Ato IV, cena 5).

Por fim, antes do início da história propriamente dita, temos duas páginas que realizam a fusão das duas linguagens, a dos mangás e a de Shakespeare:

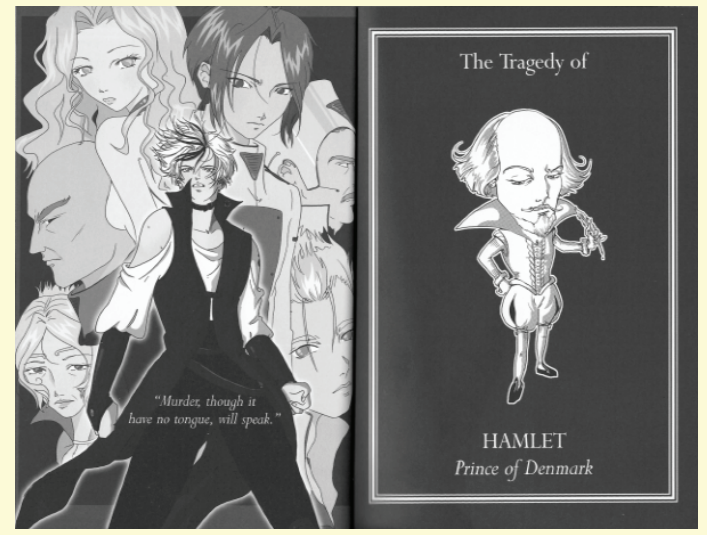

Figura 2: Frontispício da edição inglesa

Na ilustração à esquerda, uma das falas mais conhecidas do príncipe Hamlet serve de epígrafe para o que se anuncia como uma tragédia shakespeariana, tendo ao fundo alguns de seus personagens desenhados com o traço típico dos mangás. Trata-se de um fragmento do segundo solilóquio de Hamlet, que se inicia logo 
após a saída de cena dos supostos amigos Rosencrantz e Guildenstern com os versos "Now I am alone. $\mathrm{O}$ what a rogue and peasant slave am I!" (Ato II, cena 2).

A edição é complementada com um resumo do enredo e uma breve biografia de Shakespeare, nas páginas finais. Esses paratextos linguísticos compõem todos os volumes da série.

Enfocando agora a peça propriamente dita, vejamos as semelhanças e diferenças entre essa adaptação e o Hamlet original, sendo que algumas delas já foram mencionadas. Principais diferenças:

a. transposição do gênero dramático para a linguagem dos quadrinhos, e dentro desse gênero, a opção pelos mangás. É interessante observar como as imagens podem ajudar na compreensão da peça, compensando os cortes no texto. Por exemplo, na conversa com Rosencrantz e Guildenstern (Ato II, cena 2), as sucessivas expressões fisionômicas de Hamlet nas ilustrações mostram bem o seu estado de espírito. Além disso, o recurso às imagens permite explorar uma das características dos mangás, que é a violência retratada explicitamente (como no relato do assassinato de Fortimbrás da Noruega pelo rei Hamlet);

b. transposição para outra época (século XXII), com mudanças decorrentes não só da devastação climática ocorrida (embora haja vegetação nas ilustrações, esta provavelmente é fruto de projeções mentais) como também da tecnologia do futuro (as cartas se parecem com os pen drives atuais, sendo inseridas em entradas no próprio corpo das pessoas);

c. redução significativa do texto por meio de cortes e omissões, sem no entanto recorrer a fusões ou simplificações. Os fragmentos mais conhecidos são preservados, permanecendo absolutamente idênticos ao original, de modo a possibilitar um fácil reconhecimento. Vejamos o que ocorre no solilóquio "To be, or not to be" (Ato III, cena 1). Os trechos em itálico são aqueles reproduzidos no mangá e que representam, metonimicamente, esse solilóquio ${ }^{8}$ : 
HAMLET: To be, or not to be, that is the question:

Whether 'tis nobler in the mind to suffer

The slings and arrows of outrageous fortune

Or to take arms against a sea of troubles

And by opposing end them. To die - to sleep,

No more; and by a sleep to say we end

The heartache, and the thousand natural shocks

That flesh is heir to: 'tis a consummation

Devoutly to be wished. To die, to sleep;

To sleep, perchance to dream - ay, there's the rub:

For in that sleep of death what dreams may come,

When we have shuffled off this mortal coil,

Must give us pause - there's the respect

That makes calamity of so long life.

For who would bear the whips and scorns of time,

Th' oppressor's wrong, the proud man's contumely,

The pangs of dispriz'd love, the law's delay,

The insolence of office, and the spurns

That patient merit of th' unworthy takes,

When he himself might his quietus make

With a bare bodkin? Who would fardels bear,

To grunt and sweat under a weary life,

But that the dread of something after death,

The undiscover'd country, from whose bourn

No traveller returns, puzzles the will,

And makes us rather bear those ills we have

Than fly to others that we know not of?

Thus conscience does make cowards of us all,

And thus the native hue of resolution

Is sicklied o'er with the pale cast of thought, And enterprise ${ }^{9}$ of great pitch and moment

With this regard their currents turn awry

And lose the name of action. 
Quanto às semelhanças, são muitas:

a. a trama é absolutamente a mesma; a questão política tem bastante destaque, sendo que Fortimbrás aparece desde o início e tem seu papel de protagonista;

b. a ação segue a mesma sequência do original, diferentemente, por exemplo, de algumas adaptações para o cinema. No Hamlet do diretor Michael Almereyda (2000), a primeira cena é a fala de Hamlet do Ato II, cena 2, que começa com a frase: "What a piece of work is a man!";

c. os diálogos mais importantes são mantidos, reproduzindo-se, como já observado, aqueles fragmentos e expressões consagrados;

d. a linguagem original é preservada - rica, metafórica, com muitas inversões sintáticas e vocabulário sofisticado - apesar dos cortes e omissões;

e. no que diz respeito ao esquema métrico e rímico, é mantida a mesma combinação de pentâmetros jâmbicos brancos e rimados, juntamente com passagens em prosa, assim como os dísticos rimados nos trechos não cortados.

\section{A série brasileira Mangá Shakespeare e sua tradução de Hamlet}

Passo agora a enfocar um outro nível de reescrita, que é a tradução para o português do Hamlet adaptado para mangá. A editora que publica a série Mangá Shakespeare, sempre em traduções de Alexei Bueno, é a Record, através do selo Galera, que surgiu em 2007 com o objetivo de "atender a um público jovem e ávido por novidades, [oferecendo] livros que falem a sua língua e retratem temas com os quais se identifiquem" (www.galerarecord.com. $\underline{\mathrm{br}})^{10}$. Nesse selo, Shakespeare em quadrinhos convive com Meg Cabot ( $O$ diário da princesa e Tamanho 42 e pronta para arrasar, entre outros títulos), e Eoin Colfer, Cecily von Ziegesar e Suzanne 
Collins, autores respectivamente das séries de sucesso das faixas juvenil e jovem adulto Artemis Fowl, Gossip Girl e Hunger Games.

As edições da série brasileira têm o mesmo formato da inglesa, diferindo desta em pequenos detalhes. A capa da edição traduzida é idêntica à original, exceto pelo nome do tradutor que aparece ao lado do nome da ilustradora, e pela logomarca da editora brasileira. É interessante notar que o nome do adaptador, como já observado, não aparece na capa da edição em inglês, mas o do tradutor aparece na capa da edição traduzida.

A quarta capa também é bastante parecida nas duas edições, salvo algumas mudanças. Ambas trazem dois parágrafos de texto, um deles fazendo uma curta apresentação da série Mangá Shakespeare e o outro resumindo a história, além do endosso de um veículo de prestígio. Com relação às ligeiras diferenças observadas, na quarta capa da edição traduzida:

a. a) há uma curta apresentação da ilustradora e do tradutor ${ }^{11}, \mathrm{e}$ o nome do adaptador aparece, embora em fonte bem pequena (no topo da página, à esquerda);

b. b) o parágrafo de apresentação da série é o primeiro, ao contrário do que ocorre na edição original, e vem encimado por um título, "Shakespeare reinventado";

c. c) o texto do parágrafo mencionado acima não é uma tradução da sua contraparte na edição original e, sim, um outro texto, embora de função análoga. Diz a apresentação em português: "A série Mangá Shakespeare é uma nova e divertida maneira de conhecer os textos clássicos do bardo. Com o texto original e ilustrações inspiradas nos mangás japoneses, uma das mais importantes obras da literatura inglesa ganha vida a cada volume". Na edição brasileira, portanto, o parágrafo de introdução não menciona a palavra "adaptação", referindo-se apenas a uma "nova (...) maneira de conhecer os textos clássicos do bardo", e ressalta os atributos "nova" e "divertida", enquanto que no texto em inglês houve a opção por destacar o potencial da reescrita para "intrigue and 
grip readers" (ou seja, "excitar a curiosidade dos leitores e prender a sua atenção"); e

d. d) o veículo de prestígio que chancela o volume é The London Review of Books (na edição original é The Guardian).

O tradutor Alexei Bueno traz sem dúvida grande respeitabilidade ao projeto. Também poeta, editor e ensaísta, traduziu para o português As quimeras, de Gérard de Nerval, publicado pela Topbooks em edição bilíngue (1996), assim como poemas de Poe, Longfellow, Mallarmé, Tasso e Leopardi, entre outros. Como editor organizou, para a Nova Aguilar, a obra completa de vários poetas, como Augusto dos Anjos (1994), Mário de Sá-Carneiro (1995) e Álvares de Azevedo (2000), além de uma nova edição da Poesia completa e prosa de Vinicius de Moraes (1998). Pela Nova Fronteira, publicou uma edição comentada de Os Lusíadas (1993) e Grandes poemas do Romantismo brasileiro (1994). Em 1999 coorganizou a Antologia da poesia portuguesa contemporânea - um panorama, para a Lacerda Editores. Em 2006 organizou e publicou, junto com George Ermakoff, Duelos no serpentário, uma antologia da polêmica intelectual no Brasil. Em 2007 publicou pela G. Ermakoff Casa Editorial Uma história da poesia brasileira. Sua atuação transcende as fronteiras nacionais: em 2002 organizou, a convite da UNESCO, a Anthologie de la poésie romantique brésilienne, editada em Paris, e a Correspondência de Alphonsus de Guimaraens, para a Academia Brasileira de Letras, e em 2004 compilou a antologia Poesía brasileira hoxe, para a Editorial Danú, de Santiago de Compostela.

A visibilidade do tradutor na série brasileira é bem grande. Além de ter o nome na capa e uma apresentação na quarta capa, algo que não ocorre com o adaptador na edição original, há também uma "Nota do tradutor" de 21 linhas de texto logo após a folha de rosto, em posição prefacial. Na nota, o tradutor afirma que a tradução "mantém fidelidade formal absoluta aos originais, ou seja, o que é verso foi traduzido em verso, os trechos em prosa foram traduzidos em prosa, e quando havia rima esta sempre 
foi mantida" (Bueno, 2011, p. 5). A nota se detém nos aspectos formais da tradução, apresentando a estratégia tradutória global para a tradução dos trechos em verso alterados por $\operatorname{cortes}^{12}$. Já quase no final, avalia o resultado do trabalho: "Apesar da forte tendência monossilábica da língua inglesa, e do tamanho médio dos vocábulos maior em nosso idioma, a notável liberdade de sintaxe e a índole sintética do português nos possibilitaram transposições que julgamos muito satisfatórias (2011, p. 5). Encerrando a nota, Bueno enfoca aspectos lexicais e gramaticais: "Utilizamos, apenas quando necessário, um ou outro arcaísmo, e uma liberdade na topologia pronominal mais característica de outros períodos da sintaxe da nossa língua" (2011, p. 5).

Como se pode ver, portanto, a nota é bem sofisticada, expondo o projeto tradutório de Alexei Bueno e descendo a detalhes de métrica que nem todos os leitores potenciais vão entender ou querer conhecer, mas o importante é que estão ali e que o tradutor teve a oportunidade de apresentá-los.

Vejamos agora as características gerais da tradução feita. No caso das traduções de textos que já são adaptações de outros, como ressalta Nilce Pereira no seu estudo da transposição de romances de Charles Dickens para a linguagem dos quadrinhos, "o interesse da análise não se volta para como o texto foi adaptado" - o que foi abordado anteriormente, quando o foco recaiu sobre a reescrita das peças de Shakespeare sob forma de mangás - "mas para como foi traduzido a partir da adaptação" (Pereira, 2012, p. 41). Nesse tipo de análise, são consideradas as manipulações da composição física/visual do volume. Na tradução de histórias em quadrinhos, como aponta Pereira no trabalho citado, os painéis (isto é, os quadros de desenhos que compõem a página) são geralmente mantidos e o texto original é apagado e substituído pelo texto traduzido. No entanto, como ressalta a pesquisadora,

o volume pode sofrer diferentes tipos de modificações, que podem incluir mudanças no tamanho e formato do volume, adição ou subtração de cores, aumento ou diminuição de 
páginas e painéis, novos arranjos de páginas e painéis, por exemplo, como se dá na tradução de mangá, em que pode ocorrer a inversão da direção de leitura (passando da direita para a esquerda, da tradição japonesa, para a direção ocidental, da esquerda para a direita) e cortes de porções textuais e/ou imagens e/ou referências visuais (geralmente por questões de censura), embora essas últimas sejam mais incomuns. (2012, p. 42)

Como exemplo do primeiro caso de cortes, Pereira, citando autores como Heike Jüngst e Brigitte Helbling, ${ }^{13}$ menciona a omissão, na tradução, de referências a bullying e a outros temas/elementos considerados inapropriados para crianças, enquanto ilustra os demais casos com o relato da retirada da imagem da suástica no quimono de uma das personagens durante a tradução do mangá Blade of the Immortal para o alemão, já que na Alemanha a representação desse símbolo é proibida por lei (2012, p. 42).

Em relação aos aspectos linguísticos que podem sofrer modificações na tradução de quadrinhos, há quatro espaços a serem observados: os balões de diálogo, as legendas, os títulos e os paratextos linguísticos. Somente nessa última categoria houve alterações no Hamlet da série Mangá Shakespeare, as quais já foram mencionadas, com destaque para o acréscimo da "Nota do tradutor" e das informações sobre o mesmo na quarta capa. Nas demais não houve cortes, omissões ou adições, apenas a tradução stricto sensu do texto adaptado para quadrinhos em inglês, que foi apagado e substituído pelo traduzido.

Quanto à tradução propriamente dita, em especial à linguagem dentro dos balões, assim como ao esquema métrico e rímico, Alexei Bueno fez precisamente o que ele descreve na "Nota do tradutor", destacando-se os seguintes aspectos:

- emprego de "tu/vós" em vez de "você", mantendo inclusive a instabilidade entre "tu" e "vós" (thou/you) do próprio texto shakespeariano; 
- presença de vocabulário bastante sofisticado, com palavras como "faina", "negror", "encômios";

- recurso a muitas inversões sintáticas, emulando o estilo do texto de origem, como nos exemplos "vens ver de minha mãe o casamento" (Shakespeare, 2011, p. 36) e "por que te abriu a tumba as mandíbulas pétreas, e voltaste?” (p. 49).

O resultado é a tradução bem aproximada e cuidadosa de uma adaptação que representa metonimicamente o que poderíamos chamar de prototexto, ou seja, a peça em si, dela guardando as principais características em termos de trama, de linguagem e de falas icônicas. Podemos afirmar, tentativamente, que em termos de imagem o Shakespeare desses mangás não resulta muito diferente do Shakespeare das peças: um autor que, entre outros aspectos, domina a linguagem do verso e se destaca pelo notável repertório vocabular; que busca dizer algo "sobre o homem, seu comportamento e suas relações com os seus semelhantes e com o universo em que se vive, por intermédio de uma ação" (Heliodora, 1997, p. 11). Um autor, ainda, que se dirige a um público eclético cujas diferentes expectativas procura atender, conseguindo ser alternadamente erudito, popular, filosófico, lírico e racional; em seus textos, como observa Anthony Burgess (1996), há “ação e sangue para os iletrados, belas frases para os almofadinhas, humor sutil para os refinados, palhaçada escancarada para os não refinados, assuntos amorosos para as damas, lutas, baixa comédia, truísmos filosóficos, canção e dança para todos” (p. 92). Diante disso, a série inglesa Manga Shakespeare, bem como a sua contraparte traduzida, parece uma forma instigante de difundir cada vez mais o drama shakespeariano, sobretudo entre os jovens, e de inseri-lo na contemporaneidade. 


\section{Notas}

1. http://pt.wikipedia.org/wiki/Literatura_infantojuvenil

2. Levantamento feito pela bolsista PIBIC (2013-2014) Marcela Lanius, do Bacharelado em Letras - Tradutor (Inglês-Português) da PUC-Rio.

3. HATTNHER, A. L. ; PICOLO, C. M. Mangá e cinema: algumas questões de adaptação como tradução em Kill Bill (2004) e Yuki (1972). In: IV encontro Internacional de Tradutores/X Encontro Nacional de Tradutores, 2011, Ouro Preto. Caderno de Resumos, 2011. p. 438-450.

4. "Charles Dickens nos Quadrinhos Traduzidos", estudo que integra a pesquisa pós-doutoral de Nilce Pereira, sobre o tema Ilustração \& tradução: as funções tradutológicas da imagem no livro ilustrado, realizada com financiamento da Fapesp em 2012, e "Translational Aspects of Shakespeare in Comics: Then and Now", trabalho apresentado na IV Jornada Shakespeariana, realizada na USP em outubro de 2012.

5. Até setembro de 2014.

6. Texto divulgado na página www.mangashakespeare.com da editora SelfMadeHero: "The Manga Shakespeare editorial team is led by a leading Shakespeare scholar and an educational editor. Advised by teachers and other educationalists, the team is expert in making serious works of literature more accessible."

7. Os demais títulos traduzidos até setembro de 2014 são: Romeu e Julieta, A tempestade, Ricardo III e Sonho de uma noite de verão.

8. Para a versão integral do solilóquio, reproduzo o texto fixado por Harold Jenkins para o Hamlet da série The Arden Shakespeare (Routledge, 1982). No mangá em inglês há ligeiras diferenças em pontuação.

9. No texto do mangá, a palavra está no plural - enterprises - provavelmente para transformá-la em um sujeito plausível para lose. 
10. Último acesso em 13 de setembro de 2014.

11. Reproduzimos aqui a apresentação do tradutor, pelo fato de valorizá-lo bastante: "Alexei Bueno é um dos mais premiados e cultuados poetas brasileiros. Além de livros de poesia, publicou vários textos críticos e antologias, assim como organizou obras completas e traduziu diversos autores."

12. "Mesmo nos momentos em que o decassílabo branco inglês - verso de eleição da obra shakespeariana - foi alterado por cortes, preferimos traduzir todo o recho em decassílabos brancos portugueses. Quando o verso é cortado no final de uma fala - e não se completando no primeiro verso da fala seguinte - ele é igualmente cortado em português, reduzido a um dos possíveis pés constitutivos do decassílabo, ou seja, destacadamente os quadrissílabos, hexassílabos ou octossílabos. Deste modo o leitor poderá apreciar o andamento poético da peça, guardadas as diferenças de índole das línguas.” (Bueno, 2011, p. 5)

13. Respectivamente em JÜNGST, Heike. Translating Manga. In: ZANETTIN, Federico (Ed.) Comics in Translation. Manchester: St. Jerome, 2008, p. 50-78; e HELBLING, Brigitte. Und das Herz macht dodom [And the Heart Beats dodom], Kölner Stadt-Anzeiger, 25/26 August 2001, Section Moderne Zeiten, n.p.

\section{Referências}

BRISO Caio Barretto. O papel dos games. VejaRio, Rio de Janeiro, ano 22, n. 35, p. 32-34, 28, ago 2013.

BUENO, Alexei. Nota do tradutor. In: SHAKESPEARE, William. Hamlet: mangá Shakespeare. Adaptação de Richard Appignanesi, ilustrações de Emma Vieceli, tradução de Alexei Bueno. Rio de Janeiro: Galera Record, 2011.

BURGESS, Anthony. A literatura inglesa. Tradução brasileira de Duda Machado. São Paulo: Ática, 1996. 
CATÁLOGO de Literatura Infantil e Juvenil 2013 - Grupo Autêntica. http:// grupoautentica.com.br/download/catalogo-infantil-por.pdf.

FREITAS, Guilherme. Evento registra em 2013 o maior público jovem de sua história. O Globo, Rio de Janeiro, ano 88, Editoria Rio, p. 16, 9 set 2013

HELIODORA, Barbara. Falando de Shakespeare. São Paulo: Perspectiva; Rio de Janeiro: FUNARTE, 1997.

LEFEVERE, André. Tradução, reescrita e manipulação da fama literária. Trad. Claudia Matos Seligmann. Bauru, SP: Edusc, 2007.

MEIRELES, Mauricio. Loja de quadrinhos comemora aumento das vendas na Bienal. O Globo, Rio de Janeiro, ano 88, Editoria Rio, p. 13, 6 set 2013.

PEREIRA, Nilce M. Ilustração \& tradução: as funções tradutológicas da imagem no livro ilustrado. Relatório de atividades de pós-doutorado apresentado à Fapesp, 2012 (inédito).

SANDERS, Julie. Adaptation and Appropriation. London/New York: Routledge, 2006.

SHAKESPEARE, William. Hamlet. The Arden Shakespeare. Editado por Harold Jenkins. London/New York: Routledge, 1982.

. Hamlet: Manga Shakespeare. Adapted by Richard Appignanesi, illustrated by Emma Vieceli. London: SelfMadeHero, 2007.

. Hamlet: mangá Shakespeare. Adaptação de Richard Appignanesi, ilustrações de Emma Vieceli, tradução de Alexei Bueno. Rio de Janeiro: Galera Record, 2011.

SITE do Grupo Editorial Record. Disponível em: www.record.com.br. Acesso em 10 dez 2013.

SITE do Grupo Autêntica. Disponível em: www.grupoautentica.com.br. Acesso em 10 dez 2013. 
VASCONCELLOS, Pedro Vicente Figueiredo. Mangá-Dô, os caminhos das histórias em quadrinhos japonesas. Rio de Janeiro, 2006. Dissertação (Mestrado em Design) - PUC-Rio, Departamento de Artes e Design, Rio de Janeiro, 2006.

Recebido: 23-03-14

Aceito: 15-06-14 